\title{
Resource use efficiency of milk production across different herd sizes of buffaloes and crossbred cows in Middle Gujarat
}

\author{
Maitri Satashia ${ }^{1}$, RS Pundir² and VB Darji ${ }^{3}$
}

Received: 12 June 2021 / Accepted: 31 October 2021 / Published online: 21 December 2021

(C) Indian Dairy Association (India) 2021

\begin{abstract}
The most important objective of any production unit is to co-ordinate and utilize the various resources of production in such a manner that they yield the highest net returns. As farmers are shifting from low input-low output to high input-high output and traditional and subsistence to commercial dairy farming, this study assesses the impact of resources being used optimally through herd size categories by the dairy farmers for buffaloes and crossbred cows in the Middle Gujarat region. The resource use efficiency analysis helps the dairy farmers in taking appropriate decisions regarding resource allocation without using additional resources for enhancing their income. The findings show that on an average, the costs of human labour, green fodder and concentrates had significant influence on milk yield for buffalo milk production while costs of human labour, green fodder, concentrates and veterinary and medical charges had significant influence on milk yield for crossbred cow milk production implying that one per cent increase in the use of these inputs can led to increase in the gross returns from milk. Milk production for buffaloes was in decreasing returns to scale while on an overall basis, milk production for crossbred cows was increasing returns to scale. Further, the difference between MVP and its acquisition
\end{abstract}

\footnotetext{
${ }^{1}$ Department of Agricultural Economics, B. A. College of Agriculture, Anand Agricultural University, Anand - 388110, Gujarat, India.

Email: msatashia@yahoo.co.in

${ }^{2}$ International Agri-Business Management Institute, Anand Agricultural University, Anand - 388110, Gujarat, India.

Email: rspundir@aau.in

${ }^{3}$ College of Agricultural Information Technology, Anand Agricultural University, Anand - 388110, Gujarat, India

Email: vbdarji@aau.in

Maitri Satashia $(\square)$

Department of Agricultural Economics, B. A. College of Agriculture, Anand Agricultural University, Anand - 388110, Gujarat, India.

E-mail: msatashia@yahoo.co.in
}

unit price for human labour in small category, green fodder in overall category and dry fodder in marginal category in buffalo milk production and price for human labour in medium and overall category and green fodder in large category in crossbred cow milk production were found positive and significant indicating that the dairy farmers have an opportunity to increase their profit by using more of these inputs on their farms. Thus, the study concluded that only in crossbred cows, milk production was size neutral.

Keywords: Milk production, Cobb-douglas production function, Resource use efficiency, Returns to scale

\section{Introduction}

Over the years, the dairy sector in India has grown substantially and is considered as the most significant economic backbone of rural India. It is also well-known as 'oyster' of the dairy industry worldwide contributing about 28.4 per cent in the agricultural Gross Domestic Product in India and also provides gainful employment all round the year to 16.44 million people (GoI, 2020). Due to the significant negative impact of climate change on agricultural output, the dairy industry has emerged as a reliable source of income and has made significant progress in recent years (Mohapatra et al. (2021)). In order to double the income of the farmers, it is important to focus mainly on the dairy sector especially for the landless labourers, marginal and small categories of farmers and women. To a larger extent, $71 \%$ women are involved in most of the work related to animal management which has a significant impact on resource use and its efficiency (GoI, 2012). To be specific, women in India contribute in dairy production ranging from $70.5 \%$ in $1993-94$ to $76.6 \%$ in $2004-05$ (GoI, 2017). Dairy sector provides regular income and is an important source of supplementary income to the farmers in the country. India is the global leader in milk production since 1998 achieving an annual output of 198.40 million tonnes during the year 2019-20 (www.indiastat.com). The milk production of the state in the year 2019-20 was 15292000 tonnes (www.indiastat.com) and per capita average milk availability was 595 grams per day during the year 2018-19(GoG, 2020). 
Among all the species of animals, crossbred cows have been gaining importance in the state milk production. The principal driver of the growth in milk production in the state is largely due to incremental animal numbers. However, a single most significant factor that could augment milk production across any type of species is the yield of the lactating animals (Shah and Dave, 2010). Farmers are shifting from low input-low output to high input-high output and traditional and subsistence to commercial dairy farming. Therefore, to ensure optimal use of various resources by the dairy farmers is of primary concern; helping them taking appropriate decisions regarding resource allocation without using additional resources in enhancing their income. Hence, the present study examines the resource use efficiency in milk production across different herd size categories. The following hypotheses were formulated to examine the resource use efficiency:

$\mathrm{H}_{0}$ : There is no significant difference in the resource use efficiency between different types of milch animals within and across different types of herd size categories

$\mathrm{H}_{\mathrm{a}}$ : There is significant difference in the resource use efficiency between different types of milch animals within and across different types of herd size categories

\section{Materials and Methods}

\section{Data}

This study is based on primary data collected from the dairy farmers during the agricultural year 2018-19 by interviewing the respondents through a pre-tested structured schedule. A multi stage random sampling design procedure was adopted for the study to select the ultimate sampling units. In the first stage, among the nine districts of Middle Gujarat, three districts namely Anand, Kheda and Panchmahal were selected as they constituted highest milk production (Table 1). At the second stage, two talukas were randomly selected from each selected district. In the third stage, four villages were selected purposively ensuring that these villages have buffaloes as well as crossbred cows in the selected talukas. In the fourth stage, from a set of four villages chosen, falling under each taluka, 40 household, 20 each having buffaloes and 20 crossbred cows, were selected in such a way that from each selected category of marginal (1-2), small (3-5), medium (610 ) and large (above 10 milch animals) farmers, 05 households with buffaloes only and 05 households with crossbred cows only were ensured (Lal and Chandel, 2016). The classification of categories was done according to possession of milch animals. Thus, in all, 240 respondents (59 marginal, 60 small, 59 medium and 62 large) spread over 24 villages of three districts comprised as the ultimate sample size.

\section{Methodology}

To calculate the resource use efficiency of milk production on the dairy farms, the Cobb-Douglas production function was used taking gross income of milk as dependent variable and other variables i.e., cost of human labour, green fodder, dry fodder, concentrates and cost of veterinary and medical charges as explanatory variables (Kumar and Singh, 2004). The analysis was carried out on per household basis using the SPSS software. $\mathbf{Y}=\mathbf{a} \cdot \mathbf{x}_{\mathbf{i}}^{\mathbf{b i}} \cdot \mathbf{e}^{\mathbf{u}}$

This helps to capture the ability of the farmer to achieve the maximum realizable output with the given level of inputs under the existing situation and given technology.

The function for variable inputs can be written as:

$Y=a \cdot x_{1}^{b 1} \cdot x_{2}^{b 2} \cdot x_{3}^{b 3} \cdot x_{4}{ }^{b 4} \cdot x_{5}{ }^{b 5} \cdot e^{\mathrm{u}}$

The original equation (1) was converted into natural log form and the parameters were estimated by using the Ordinary Least Squares method.

$\ln Y=\ln a+b_{1} \ln x_{1}+b_{2} \ln x_{2}+b_{3} \ln x_{3}+b_{4} \ln x_{4}+b_{5} \ln x_{5}+U$

Where,

$\mathrm{Y}=$ Gross income from milk per farm per day,

$\mathrm{a}=$ Intercept,

$\mathrm{X}_{1}=$ Cost of human labour (Rs per farm per day)

$\mathrm{X}_{2}=$ Cost of green fodder (Rs per farm per day)

Table 1 District wise milk production in Middle Gujarat

\begin{tabular}{llllll}
\hline Name of the Districts & $2014-15$ & $2015-16$ & $2016-17$ & Average & Per cent to Total \\
\hline Ahmedabad & 404.38 & 425.48 & 435.83 & 421.89 & 14.05 \\
Anand* & 523.38 & 550.88 & 579.15 & 551.13 & 18.35 \\
Dahod & 290.34 & 304.00 & 298.39 & 297.57 & 9.91 \\
Kheda* & 622.90 & 683.58 & 705.67 & 670.71 & 22.34 \\
Panchmahal* & 554.93 & 608.31 & 644.01 & 602.41 & 20.06 \\
Vadodara & 451.68 & 441.16 & 482.47 & 458.43 & 15.27 \\
Total & 2847.61 & 3013.41 & 3145.52 & 3002.18 & 100.00 \\
\hline
\end{tabular}

Source: GoG, 2017

Note: * Considered for study. 
$X_{3}=$ Cost of dry fodder (Rs per farm per day)
$X_{4}=$ Cost of concentrate (Rs per farm per day)
$X_{5}=$ Cost of veterinary and medical charges (Rs per farm per day)

$b_{1}, b_{2}, \ldots, b_{5}=$ Regression co-efficients (output elasticity of respective inputs $\left(\mathrm{X}_{\mathrm{i}}\right.$ 's))

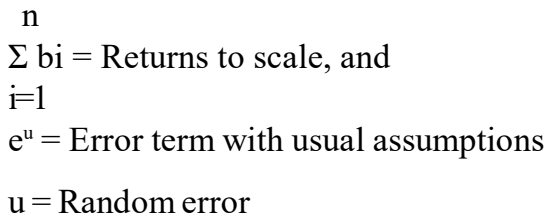

A criterion used to measure returns to scale is as follows:

$$
\begin{aligned}
& \Sigma \mathrm{E}_{\mathrm{p}}>1 \text { : increasing returns to scale } \\
& \Sigma \mathrm{E}_{\mathrm{p}}=1 \text { : constant returns to scale } \\
& \Sigma \mathrm{E}_{\mathrm{p}}<1 \text { : decreasing returns to scale. }
\end{aligned}
$$

\section{Marginal value productivity (MVP)}

Marginal value product of a particular input was calculated by taking the first order partial derivative of the output $(Y)$ function with respect to corresponding inputs $\left(\mathrm{X}_{\mathrm{i}}\right)$. The regression coefficients of inputs obtained were used to calculate marginal value products (MVP) at their geometric mean.

MVPxi $=$ bi $\frac{\bar{Y}}{\bar{X}}$

Where,

$$
\begin{aligned}
& Y=\text { Geometric mean of output }(Y), \\
& X=\text { Geometric mean of respective inputs }\left(x_{i}\right) \text { and } \\
& b_{i}=\text { Regression co-efficient associated with the } x_{i} \text { input. }
\end{aligned}
$$

\section{MVP in relation to marginal factor costs (MFC)}

The basic criterion of an efficient resource use is that the MVP of the input just covers the marginal factor cost, which is $\mathrm{MVP}_{\mathrm{Xi}}=$ $\mathrm{P}_{\mathrm{Xi}}$. Hence, for evaluating the efficiency of resource use, the ratio of marginal value product for different factors to their respective factor cost was estimated. If the marginal contribution of one unit of input is greater than the price of the input, then the farmers is said to be allocating the resources efficiently and as such there is further scope for allocating more unit of that particular input. If the marginal contribution is negative, then the farmers are said to be using the input excessively so that the fixed resources are no longer responsive to the variable input applied.
The criterion used for determining the optimality of resource use is as follows,

$$
\begin{aligned}
& \text { MVP/MFC }>1 \text { : under-utilization of resources } \\
& \text { MVP/MFC }=1 \text { : optimal use of resources } \\
& \text { MVP/MFC }<1 \text { : over-utilization of resources. }
\end{aligned}
$$

Any deviation of MVP of input $i$ from its unit price may be termed as resource use inefficiency. The higher the difference between MVP of an input and its price, the higher the resource use inefficiency and vice versa. Further, t-statistics was used to test the statistical significance of the difference between the MVP of an input and its unit price. The t-statistics that was used is computed as follows:

$$
\begin{gathered}
\mathrm{t}=\mathrm{MVP}_{\mathrm{Xi}}-\mathrm{P}_{\mathrm{Xi}} \\
\operatorname{SE}\left(\mathrm{MVP}_{\mathrm{Xi}}\right) \\
\mathrm{SE}\left(\mathrm{MVP}_{\mathrm{Xi}}\right)=\operatorname{SE}\left(\mathrm{b}_{\mathrm{i}}\right) \overline{\mathrm{Y}}
\end{gathered}
$$

\section{$\overline{\mathrm{X}}$}

Where,

$\mathrm{MVP}_{\mathrm{Xi}}=$ Marginal value productivity of $\mathrm{X}_{\mathrm{i}}$ resource,

$\mathrm{P}_{\mathrm{Xi}}=$ Price per unit of $\mathrm{X}_{\mathrm{i}}$ resource,

SE $\left(b_{i}\right)=$ Standard error of regression co-efficient associated with $\mathrm{X}_{\mathrm{i}}$ resource and

$\overline{\mathrm{Y}}$ and $\overline{\mathrm{X}}=$ Geometric means of regression co-efficient associated with $\mathrm{X}_{\mathrm{i}}$ resource.

The absolute value of calculated ' $t$ ' was compared with table value of ' $t$ ' in case of all inputs at (n-k-1) degrees of freedom where ' $n$ ' is the total number of observations and ' $k$ ' is the total number of explanatory variables. If calculated ' $t$ ' was less than table value of ' $t$ ', then it was concluded that the difference between the marginal value product of a resource and its acquisition unit price were statistically insignificant, indicating the optimal use of this resource and vice-versa.

\section{Results and Discussion}

\section{Resource use efficiency}

The productivity of resources used for milk production obtained by the production function (intercept, co-efficient of multiple determination and returns to scale) is depicted in the Table 2 for buffaloes and Table 4 for crossbred cows.

The production function for buffalo milk (Table 2) reveals that the co-efficient of multiple determinations $\left(\mathrm{R}^{2}\right)$ was 0.92 which 
showed that $92.25 \%$ variation in the gross return was explained by the model using explanatory variables $\left(\mathrm{X}_{1}\right.$ to $\left.\mathrm{X}_{5}\right)$ in the selected regression model. In case of marginal, small, medium and large size categories, the corresponding values of $\mathrm{R}^{2}$ were $58.70 \%$, $58.85 \%, 81.50 \%$ and $80.11 \%$, respectively. Further, the results showed that the elasticities were positive as well as negative. It is inferred that among the explanatory variables, cost of green fodder was found positive in all the categories whereas cost of human labour in medium and large categories, cost of dry fodder in large category, cost of concentrates in marginal and small categories and cost of veterinary and medical charges in marginal, small and medium categories were found negative.

The output elasticity of human labour $\left(\mathrm{X}_{1}\right)$ was statistically significant at $1 \%$ and $5 \%$ level of significance in small and overall categories, respectively, which implies the increased usage of labour and thus the gross returns implying that with one per cent increase in labour cost, gross returns will increase by $0.70 \%$ and $0.22 \%$ in small and overall categories, respectively.

Green fodder appeared to be an important variable influencing buffalo milk production. The elasticity of green fodder $\left(\mathrm{X}_{2}\right)$ was statistically significant at $5 \%$ and $1 \%$ level of significance in large and overall categories, respectively, which implies that one per cent increase in the expenditure on green fodder resulted in an increase of $0.27 \%$ and $0.35 \%$ in large and overall categories, respectively, in returns from milk production.

On an overall basis, expenditure on dry fodder $\left(\mathrm{X}_{3}\right)$ was found to be statistically non-significant. This indicated that there was

Table 2 Production elasticities for different category of farms of buffalo milk

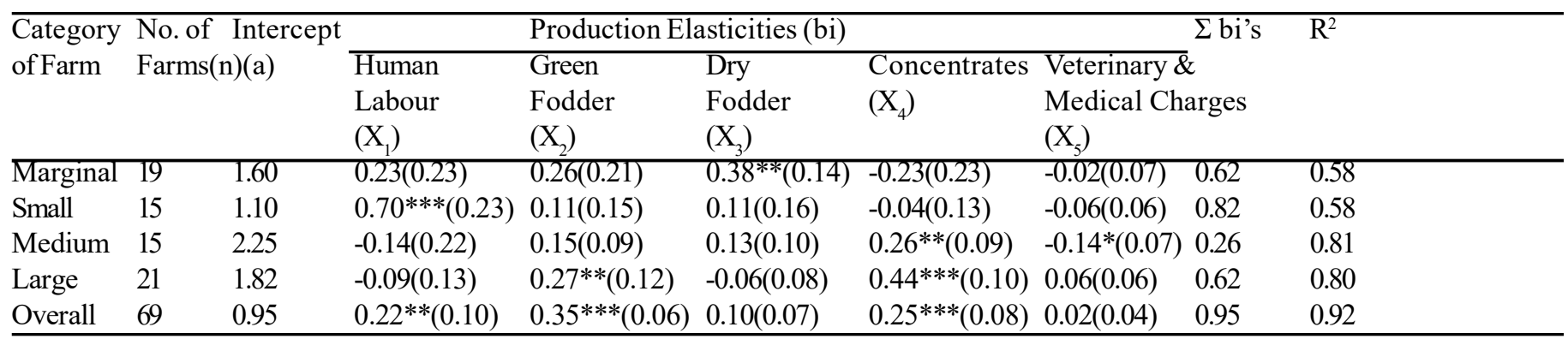

Source: Field Survey

Note: Figures in the parentheses indicate standard error of corresponding elasticity.

***Significant at 1 per cent level of significance

**Significant at 5 per cent level of significance

*Significant at 10 per cent level of significance

Table 3 Comparison of MVPs of inputs with their prices for buffalo milk production across herd size categories

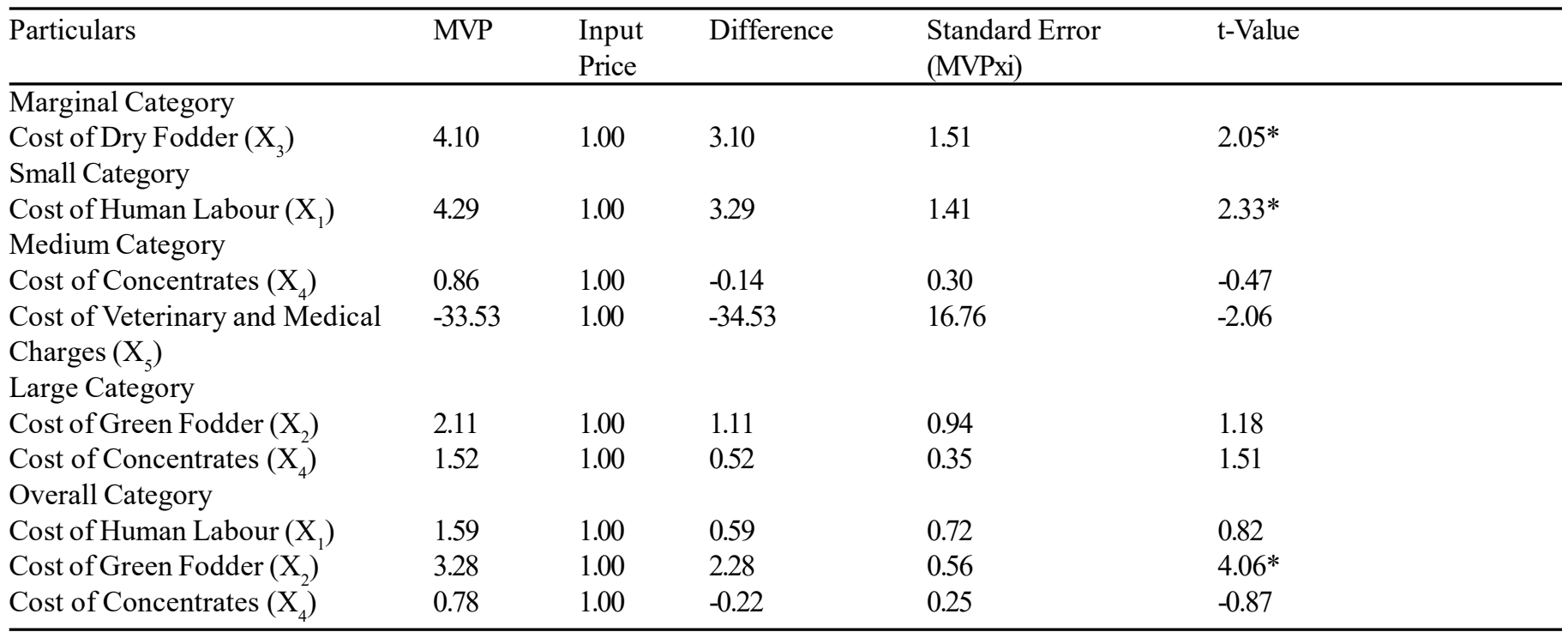

Source: Field Survey

* Significant at 5 per cent level of significance. 
no significant impact of feeding of dry fodder to buffaloes on returns from milk production. The reason might be that the data were collected in winter season, which was the flush season for green fodder and farmers were found efficiently utilizing green fodder in the study area. Non-significant impacts of dry fodder on buffaloes were also reported by Ajara and Patel (2008), Thakur and Dhaka (2010) and Sharma et al. (2014).

Among the feed inputs, expenditure on concentrates was observed to be second most important variable significantly influencing returns from milk production. The elasticity of concentrates $\left(\mathrm{X}_{4}\right)$ was statistically significant $(\mathrm{P}<0.05)$ in medium category and statistically highly significant $(\mathrm{P}<0.01)$ in large and overall categories, implying that one per cent increase in the expenditure on concentrates resulted in an increase of $0.26 \%$, $0.44 \%$ and $0.25 \%$ in medium, large and overall categories, respectively, in returns from milk production.

On an overall basis, the elasticity of veterinary and medical expenditure $\left(\mathrm{X}_{5}\right)$ was found statistically non-significant. Therefore, expenditure on veterinary and medical services had no impact on returns from milk production.

The significant impact of human labour, green fodder and concentrates on returns from buffalo milk production were in conformity with the findings of the earlier research work reported by Ajara and Patel (2008), Parmar et al. (2010) and Kumari and Malhotra (2018).

\section{Returns to scale for buffalo milk production}

The value of sum of regression co-efficients ( $\Sigma$ bi's) was observed to be less than one in all the categories of farm indicating that the buffalo milk production is decreasing returns to scale or in other words, sample farmers were observed operating in the second zone of production where area of economic relevance is present within the boundaries of the zone. Zone-II, also called rational zone, depicts somewhere optimum use of inputs representing the range of rational production decisions. Similar results were reported by Parmar et al. (2010).

\section{MVP to MFC for buffalo milk production}

A perusal of Table 3 indicates that the difference between MVP and its acquisition unit price for human labour in overall category and green fodder and concentrates in large categories were positive and non-significant indicating that the use of these inputs by the dairy farmers were optimal and being utilized efficiently and there was no need to increase or decrease its use. The positive and non-significant impact of human labour was also reported by Kumari and Malhotra, (2018).

The difference between MVP and its acquisition unit price for human labour in small category, green fodder in overall category and dry fodder in marginal category were positive and significant which indicated that these inputs were being under-utilized implying that there is a scope to further increase the yield of buffalo milk. The positive and significant impact of green fodder was in conformity with the findings of the earlier research work reported by Mehra et al. (2018).

Further, the difference between MVP and its acquisition unit price for concentrates in medium and overall categories were negative and non-significant indicating that concentrates were being overutilized and there was a need to decrease its use. The negative and non-significant impact of concentrates was also reported by Mehra et al. (2018).

The production function for crossbred cow milk (Table 4 ) revealed that the co-efficient of multiple determinations $\left(\mathrm{R}^{2}\right)$ was 0.92 which showed that $92.94 \%$ variation in the gross return was explained by the model using explanatory variables $\left(X_{1}\right.$ to $\left.X_{5}\right)$ in the selected regression model. In case of marginal, small, medium and large size categories, the corresponding values of $\mathrm{R}^{2}$ were $55.85 \%$, $61.93 \%, 64.15 \%$ and $91.49 \%$, respectively. Further, the results showed that the elasticities were positive as well as negative. It

Table 4 Production elasticities for different category of farms of crossbred cow milk

\begin{tabular}{|c|c|c|c|c|c|c|c|c|c|}
\hline \multirow{3}{*}{$\begin{array}{l}\text { Category } \\
\text { of Farm }\end{array}$} & \multicolumn{3}{|c|}{$\begin{array}{ll}\text { No. } & \text { Intercept }\end{array}$} & \multicolumn{4}{|c|}{ Production Elasticities (bi) } & \multicolumn{2}{|c|}{$\overline{\Sigma \text { bi's } R^{2}}$} \\
\hline & \multirow{2}{*}{\multicolumn{2}{|c|}{$\begin{array}{l}\text { of Farms (a) } \\
\text { (n) }\end{array}$}} & \multirow{2}{*}{$\begin{array}{l}\text { Human } \\
\text { Labour } \\
\left(X_{1}\right)\end{array}$} & \multirow{2}{*}{$\begin{array}{l}\text { Green } \\
\text { Fodder } \\
\left(\mathrm{X}_{2}\right)\end{array}$} & \multirow{2}{*}{$\begin{array}{l}\text { Dry } \\
\text { Fodder } \\
\left(\mathrm{X}_{3}\right)\end{array}$} & \multirow{2}{*}{$\begin{array}{l}\text { Concen-trates } \\
\left(\mathrm{X}_{4}\right)\end{array}$} & \multirow{2}{*}{$\begin{array}{l}\text { Veterinary \& } \\
\text { Medical } \\
\text { Charges }\left(\mathrm{X}_{5}\right)\end{array}$} & & \\
\hline & & & & & & & & & \\
\hline & 22 & 0.75 & $0.49 *(0.25)$ & $0.19(0.19)$ & $0.06(0.16)$ & $0.29(0.18)$ & $0.00(0.08)$ & 1.05 & 0.55 \\
\hline Small & 25 & 1.34 & $0.32 *(0.18)$ & $0.16(0.13)$ & $0.14(0.14)$ & $0.12(0.12)$ & $0.14^{* *}(0.06)$ & 0.91 & 0.61 \\
\hline Medium & 23 & 0.37 & $0.76^{* * *}(0.20)$ & $0.06(0.21)$ & $-0.02(0.16)$ & $0.35 * * *(0.13)$ & $0.00(0.04)$ & 1.17 & 0.64 \\
\hline Large & 25 & 1.26 & $-0.08(0.18)$ & $0.49 * * *(0.15)$ & $-0.04(0.09)$ & $0.42 * * *(0.15)$ & $0.11^{* *}(0.05)$ & 0.90 & 0.91 \\
\hline Overall & 95 & 0.86 & $0.37^{* * *}(0.12)$ & $0.23 * * *(0.08)$ & $0.00(0.08)$ & $0.34 * * *(0.09)$ & $0.04 *(0.04)$ & 1.01 & 0.92 \\
\hline
\end{tabular}

Source: Field Survey

Note: Figures in the parentheses indicate standard error of corresponding elasticity.

$* * *$ Significant at 1 per cent level of significance

** Significant at 5 per cent level of significance

* Significant at 10 per cent level of significance 
is inferred that among the explanatory variables, cost of human labour was found positive in all the categories except large category whereas cost of dry fodder in medium and large categories were found negative. Therefore, earlier formed hypothesis $\mathrm{H}_{0}$, that resource use efficiency was same between different types of milch animals within and across different types of herd size categories is rejected.

The output elasticity of human labour $\left(\mathrm{X}_{1}\right)$ was statistically significant at $10 \%$ level of significance in marginal and small categories and statistically highly significant $(\mathrm{P}<0.01)$ in medium and overall categories which implies the increased usage of labour and thus the gross returns implying that with one per cent increase in labour cost, gross returns will increase by $0.49 \%$, $0.32 \%, 0.76 \%$ and $0.37 \%$ in marginal, small, medium and overall categories, respectively. Significant impacts of human labour on returns from crossbred cow milk production were in conformity with the findings of Kumari and Malhotra (2018) and Singh and Singh (2018).

The elasticity of green fodder $\left(\mathrm{X}_{2}\right)$ was statistically highly significant $(\mathrm{P}<0.01)$ for large and overall categories, which implies that one per cent increase in the expenditure on green fodder resulted in an increase of $0.49 \%$ and $0.23 \%$ in large and overall categories, respectively, in returns from milk production. Thakur and Dhaka (2010) and Sharma et al. (2014) also reported that green fodder was of great importance and had significant impact on crossbred cow milk production.

On an overall basis, expenditure on dry fodder $\left(\mathrm{X}_{3}\right)$ was found to be statistically non-significant. This indicated that there was no significant impact of feeding of dry fodder to crossbred cows on returns from milk production. The reason might be that the data were collected in winter season, which was the flush season for green fodder and farmers were found efficiently utilizing green fodder in the study area. Non-significant impacts of dry fodder on crossbred cows were also reported by Ajara and Patel (2008) and Sharma et al. (2014).

The concentrate feed as anticipated, demonstrated its significant positive influence on milk yield in crossbred cows. The high milk producing crossbred cows have an innate high demand for nutrients, which has to be met by concentrate feeds. In realizing higher milk yields from crossbred cows, concentrate feeds have crucial significance. This reveals that for sustaining the milk production from crossbred cows, measures to augment the supply of concentrate feeds are very critical. The elasticity of concentrates $\left(\mathrm{X}_{4}\right)$ was statistically highly significant at $1 \%$ level of significance in medium, large and overall categories, implying that one per cent increase in the expenditure on concentrates resulted in an increase of $0.35 \%, 0.42 \%$ and $0.34 \%$ in medium, large and overall categories, respectively, in returns from milk

Table 5 Comparison of MVPs of inputs with their prices for crossbred cow milk production across herd size categories

\begin{tabular}{|c|c|c|c|c|c|}
\hline Particulars & MVP & $\begin{array}{l}\text { Input } \\
\text { Price }\end{array}$ & Difference & $\begin{array}{l}\text { Standard Error } \\
\text { (MVPxi) }\end{array}$ & t-Value \\
\hline$\overline{\text { Marginal Category }}$ & & & & & \\
\hline $\begin{array}{l}\text { Cost of Human Labour }\left(X_{1}\right) \\
\text { Small Category }\end{array}$ & 3.52 & 1.00 & 2.52 & 1.79 & 1.40 \\
\hline Cost of Human Labour $\left(\mathrm{X}_{1}\right)$ & 2.43 & 1.00 & 1.43 & 1.37 & 1.05 \\
\hline $\begin{array}{l}\text { Cost of Veterinary and } \\
\text { Medical Charges }\left(\mathrm{X}_{5}\right) \\
\text { Medium Category }\end{array}$ & 78.43 & 1.00 & 77.43 & 33.61 & $2.30^{*}$ \\
\hline Cost of Human Labour $\left(\mathrm{X}_{1}\right)$ & 5.67 & 1.00 & 4.67 & 1.49 & $3.13^{* *}$ \\
\hline $\begin{array}{l}\text { Cost of Concentrates }\left(\mathrm{X}_{4}\right) \\
\text { Large Category }\end{array}$ & 1.38 & 1.00 & 0.38 & 0.51 & 0.75 \\
\hline Cost of Green Fodder $\left(\mathrm{X}_{2}\right)$ & 4.68 & 1.00 & 3.68 & 1.43 & $2.57 * *$ \\
\hline Cost of Concentrates $\left(\mathrm{X}_{4}\right)$ & 1.86 & 1.00 & 0.86 & 0.66 & 1.30 \\
\hline Cost of Human Labour $\left(\mathrm{X}_{1}\right)$ & 2.88 & 1.00 & 1.88 & 0.93 & $2.01 *$ \\
\hline Cost of Green Fodder $\left(\mathrm{X}_{2}\right)$ & 2.12 & 1.00 & 1.12 & 0.74 & 1.52 \\
\hline Cost of Concentrates $\left(\mathrm{X}_{4}\right)$ & 1.44 & 1.00 & 0.44 & 0.38 & 1.15 \\
\hline $\begin{array}{l}\text { Cost of Veterinary and } \\
\text { Medical Charges }\left(\mathrm{X}_{5}\right)\end{array}$ & 16.43 & 1.00 & 15.43 & 16.43 & 0.94 \\
\hline
\end{tabular}

Source: Field Survey

** Significant at 1 per cent level of significance

* Significant at 5 per cent level of significance 
production. Significant impact of concentrates on crossbred cows were reported by Ajara and Patel (2008), Thakur and Dhaka (2010), Sharma et al. (2014), Kumari and Malhotra (2018) and Singh and Singh (2018).

On an overall basis, the elasticity of veterinary and medical expenditure $\left(\mathrm{X}_{5}\right)$ was also found to be statistically significant $(\mathrm{P}<0.10)$. This suggested that on an average, one per cent increase in the expenditure on veterinary and medical services, resulted in an increase of $0.04 \%$ returns from milk production in crossbred cows. The significant impact of veterinary and medical expenditure on crossbred cows was also reported by Singh and Singh (2018).

\section{Returns to scale for crossbred cow milk production}

In the present study, the value of sum of regression co-efficients ( $\Sigma$ bi's) was observed to be more than one in all the categories of farm except small and large categories, indicating that the crossbred cow milk production is increasing returns to scale or in other words, sample farmers were observed operating in the first zone of production. Zone-I is called irrational zone because the average product increases throughout the zone indicating that the efficiency of all the variable inputs keeps on increasing. So, farmer should not stop in this zone and he must produce up to the level where average product is maximum. Input-use should be continued until zone-II. Hence, it is not reasonable to stop using an input when its efficiency is increasing. If he stops in this region, some of his resource will remain unused or underutilized. In case of crossbred cows on overall basis, 1 per cent increase in the input variables $\left(X_{1}\right.$ to $\left.X_{5}\right)$ will result in increase of 1.01 per cent in gross returns. Thus, it is concluded that only in crossbred cows, milk production is size neutral.

\section{MVP to MFC for crossbred cow milk production}

A perusal of Table 5 indicates that the difference between MVP and its acquisition unit price for human labour in marginal and small categories, green fodder in overall category, concentrates in medium, large and overall categories and veterinary and medical charges in overall category were positive and non-significant indicating that the use of these inputs by dairy farmers was optimal and being utilized efficiently and there was no need to increase or decrease its use.

Further, the difference between MVP and its acquisition unit price for human labour in medium and overall categories, green fodder in large category and veterinary and medical charges in small and large categories were positive and significant which indicated that these inputs were being under-utilized implying that there is a scope to further increase the yield of crossbred cow milk through increasing the use of human labour, green fodder and veterinary and medical services.

\section{Conclusions}

This study analyzed the resource use efficiency of milk production in three districts of Middle Gujarat revealing that there is an ample potentiality of raising milk production on the sample farms through optimum utilization of resources like human labour, fodder and concentrates and with better management practices. Milk production was found to be size neutral only in case of crossbred cows in the region and hence, for increasing farmer's income and eventually livelihood, crossbred cows should be encouraged in the study area. Further, regular studies on resource use efficiency of milk production should be carried out which will help in rational pricing policy.

\section{References}

Ajara M, Patel RH (2008) An economic viability of dairy enterprises in Anand district of Middle Gujarat. Master's thesis, Anand Agricultural University, Anand

GoG (2017) $34^{\text {th }}$ Survey report on estimates of major livestock products. Directorate of Animal Husbandary, Krishi Bhavan, Sector 10-A, Gandhinagar, Gujarat

GoG (2020) Bulletin of animal husbandry and dairying statistics, 201920. Directorate of Animal Husbandary, Krishi Bhavan, Sector 10-A, Gandhinagar, Gujarat

GoI (2012) Report of the working group on Animal Husbandary and Dairying, $11^{\text {th }}$ Five Year Plan (2007-2012). Planning Commission, Government of India, New Delhi

GoI (2017) Report of the working group on Animal Husbandary and Dairying, $12^{\text {th }}$ Five Year Plan (2012-2017). Planning Commission, Government of India, New Delhi

GoI (2020) Annual report, 2019-20. Department of Animal Husbandry and Dairying, Ministry of Fisheries, Animal Husbandry and Dairying, Government of India, New Delhi

Kumar BG, Singh RV (2004) Resource use efficiency of cow milk production in Tamil Nadu. Indian J Dairy Sci 57: 137-140

Kumari B, Malhotra R (2018) Milk production function and resource use efficiency of women dairy cooperatives in Begusarai district of Bihar. Indian J Dairy Sci 71: 98-101

Lal P, Chandel BS (2016) Economics of milk production and cost elasticity analysis in Sirsa district of Haryana. Econ Affairs 61: 405-411

Mehra K, Singh V, Nazir H (2018) Resource Use efficiency in milk production and milk utilization pattern of milk producers in hilly areas of Kumaon region of Uttarakhand. Int $\mathrm{J}$ of Pure \& Applied Biosci 6: 736-743

Mohapatra S, Sendhil R, Singh A, Dixit AK, Malhotra R, Ponnusamy K (2021) An economic analysis of milk production in Haryana. Indian J Dairy Sci 74: 159-166

Parmar HC, Zala YC, Arya JS (2010) Comparative economics of milk production: A case study of Vadodara district of Gujarat. Indian J Dairy Sci 63: 408-413

Shah J, Dave D (2010) Regional trends and pattern in milk production and drivers for future growth in Gujarat state. Agric Econ Res Rev 23: 295-302

Sharma SK, Malhotra R, Mahajan S (2014) Resource-use efficiency in milk production in Malwa region of Madhya Pradesh. Indian J Dairy Sci 67: $531-534$

Singh N, Singh JM (2018) Cost-return structure of dairy farming on marginal and small farms in submountainous region of Punjab. Indian J Dairy Sci 71: 89- 97

Thakur MK, Dhaka JP (2010) Economics of production and marketing of milk in Samastipur district of Bihar. Master's Thesis, National Dairy Research Institute, Karnal

Websites retrieved on internet:

https://www.indiastat.com. Accessed on $2^{\text {nd }}$ January, 2020. 